\title{
Sob o estigma do fundamentalismo: algumas reflexões sobre um conceito controverso
}

\author{
Under the stigma of fundamentalism: \\ some reflections on a controversial concept
}

Daniel Rocha*

\begin{abstract}
Resumo
Este artigo procura discutir o atual uso inflacionado do conceito de fundamentalismo (na mídia e na reflexão acadêmica) e apresentar algumas reflexões sobre os limites e polêmicas em torno da noção de fundamentalismo. A partir da perspectiva da História dos Conceitos, especialmente das reflexões de Reinhart Koselleck, o texto procura reconstruir a história do conceito de fundamentalismo nos Estados Unidos, apresentando alguns momentos essenciais para se entender as transformações no uso do conceito ao longo do século XX. Ressalta-se a importância da diferenciação entre o "fundamentalismo histórico" (protestante e norte-americano) e sua ampliação no sentido de um "fundamentalismo global", perspectiva que ganhou força na academia a partir dos anos 1980. A partir dessas reflexões, o artigo procura apresentar um debate atual entre os defensores do uso do conceito numa perspectiva comparativa e os que consideram que a utilização de um conceito ampliado de fundamentalismo tem se tornado mais um complicador do que uma ferramenta analítica relevante nos estudos sobre a religião na contemporaneidade.
\end{abstract}

Palavras-chave: Fundamentalismo. História dos Conceitos. Religião e Política. Religião e Modernidade.

\begin{abstract}
This article seeks to discuss the current inflated use of the concept of fundamentalismo (in the media and in academic reflection) and to present some reflections about the limits and controversies surrounding the notion of fundamentalism. From the perspective of the History of Concepts, especially the reflections of Reinhart Koselleck, the text seeks to reconstruct the history of the concept of fundamentalism in America, presenting some essential moments to understand the transformations in the use of the concept throughout the 20th century. The importance of differenciating between "historical fundamentalismo" (Protestant ans American) and its expansion towards "global fundamentalism" - a perspective that gained streght in academia since the $1980 \mathrm{~s}$ - is emphasized. From this reflections, this article seeks to presente a current debate between defenders of the use of fundamentalism in a comparative perspective and those who consider that the use os an expanded concept of fundamentalism has become more a complicator than a relevant analytical tool in contemporary studies of religion.
\end{abstract}

Keywords: Fundamentalism. History of Concepts. Religion and Politics. Religion and Modernity.

\footnotetext{
Artigo submetido em 4 de março de 2020 e aprovado em 17 de agosto de 2020.

* Doutor em História pela UFMG. Bolsista do PNPD/CAPES. Professor Colaborador no PPGCR PUC Minas. País de origem: Brasil. E-mail: danielrochabhmg@gmail.com
} 


\section{Introdução}

For the moment, we may simply observe once again that the question "Is Confucianism a religion?" is one that the West has never been able to answer, and China never able to ask.

(Wilfred Cantwell Smith)

Em coluna publicada no site do The New York Times em 04 de maio de 2007, o jornalista turco Mustafa Akyol (2007) iniciou seu texto afirmando que: "Não é segredo que o fundamentalismo islâmico é uma ameaça à democracia, à liberdade e à segurança no mundo de hoje" (AKYOL, 2007). No entanto, "os mesmos valores podem ser ameaçados também pelos fundamentalistas seculares" (AKYOL, 2007). ${ }^{1}$ No decorrer do texto, Akyol (2007) discute em que implicariam tais ameaças, mas em momento algum ele se preocupa em esclarecer o que seria fundamentalismo, ou o que ele entende por fundamentalismo - que teria, inclusive sua "versão" islâmica e sua "versão" secular. Parece que se tratava de algo autoevidente e que qualquer leitor da coluna saberia com clareza do que está se falando.

Apesar de seu uso cada vez mais frequente nos debates acadêmicos, nos meios de comunicação e mesmo nas conversas de botequim, o conceito de fundamentalismo é uma inesgotável fonte de polêmica. E grande parte das controvérsias são fruto de uma recorrente falta de precisão em relação ao que se evoca quando o conceito de fundamentalismo e/ou o adjetivo fundamentalista são acionados. Fundamentalismo, no mundo contemporâneo, possui uma conotação negativa e acusatória. Religiosos intransigentes, pessoas intolerantes e pouco abertas ao diálogo (fala-se, inclusive, da existência de um "fundamentalismo ateu") e todos os rotulados como "inimigos do progresso" ganharam a pecha de fundamentalistas. Poucos são os que se assumem como fundamentalistas. O

\footnotetext{
${ }^{1}$ Tradução nossa. O mesmo ocorre em todas as citações diretas de textos originalmente em inglês ao longo do artigo. Disponível em: https://www.nytimes.com/2007/05/04/opinion/04iht-edakyol.1.5565938.html. Acesso em: 27 jul. 2020.
} 
fundamentalista está identificado no outro. Mas não em qualquer outro. O "outro fundamentalista" é uma ameaça ao nosso modo de vida, à paz, às liberdades, à democracia, à boa convivência familiar etc.

Infelizmente, a crescente familiaridade que vamos tendo com o conceito tem andado lado a lado com o aumento da falta de uma maior preocupação em precisar do que se fala quando se refere a fundamentalismo. Além disso, com sua "expansão" para além dos limites da religião, existiriam agora manifestações fundamentalistas pelo mundo afora, que prescindiriam de livros sagrados, comunidades de fé e mesmo divindades. Os pesquisadores brasileiros não têm se eximido de tal debate. Os trabalhos de Ivo Pedro Oro (1996), Martin Dreher (2006), Zwinglio Motta Dias (2009) e, mais recentemente, Breno Martins Campos (2018) trouxeram para os pesquisadores brasileiros a importância da reflexão sobre a história e os debates em relação ao(s) significado(s) de fundamentalismo. Em "Fundamentalismo e integrismo: os nomes e a coisa”, Antônio Flávio Pierucci (1992) já apresentava preocupações essenciais com a falta de precisão em relação ao uso do conceito e das confusões que se estabeleciam entre ele e termos correlatos, como integrismo e tradicionalismo. Com a apropriação do conceito pela mídia e pelos debates políticos, "seu sentido original se obtunde e se oblitera, em detrimento muitas vezes da clareza, da distinção, da precisão”. (PIERUCCI, 1992, p. 146).

Vinte e oito anos se passaram desde a publicação do texto de Pierucci, mas vários questionamentos e problemas lá levantados continuam pertinentes para os pesquisadores hoje em dia. Não apenas "requentamos" uma discussão já feita diversas vezes. Baseados em discussões recentes levantadas por autores como David Harrington Watt (2004, 2014, 2017), Gabriele Marranci (2009), Simon A. Wood (2014) e Susan Harding (1992, 2000), procuramos, de fato, nos perguntar sobre a real utilidade do uso cada vez mais ampliado que o conceito de fundamentalismo vem recebendo ao longo do tempo. Além do debate com os autores citados, entre outros, procuraremos orientar nossa discussão a partir da perspectiva da História dos Conceitos e das reflexões de Reinhart Koselleck (2006) 
para entender a trajetória do conceito de fundamentalismo e, a partir dessa trajetória, ter uma melhor compreensão das continuidades e transformações do conceito e seu significado, pois o fato de que "as palavras permaneceram as mesmas não [é], por si só, um indício suficiente da permanência do mesmo conteúdo ou significado por elas designado" (KOSELLECK, 2006, p. 105). Um conceito tem sua própria história e essa não ocorre apenas no campo da reflexão e dos debates acadêmicos. Seus usos na mídia e no senso comum em geral são fundamentais para se compreender os seus usos nos textos dos pesquisadores. De acordo com Angela de Castro Gomes (2001): "Seria impossível pensar, mesmo que simplificadamente, a trajetória acadêmica do conceito ignorando sua apropriação mais ampla, já que ela mesma passa a atuar como força de pressão e conformação dos debates que se desenvolvem sobre sua utilização de uma forma abrangente". (GOMES, 2001, p. 21).

Inicialmente, procuraremos apresentar alguns princípios básicos da História dos Conceitos e as possibilidades que ela apresenta para um entendimento mais consistente e ancorado na história de um determinado conceito, no nosso caso do fundamentalismo. Na sequência, procuraremos despir o conceito de sua "pesada" carga semântica atual e retornar à origem do vocábulo e às suas raízes protestantes e norte-americanas. Procuraremos, de maneira sucinta, apresentar o que seria o "fundamentalismo histórico" nos Estados Unidos da década de 1920 e alguns desenvolvimentos e transformações de sua compreensão frente a certos episódios ocorridos no século XX. Na terceira seção, trataremos da ampliação da discussão e do alcance que o conceito de fundamentalismo recebeu após a revolução iraniana de 1979 e a publicação dos volumes The Fundamentalism Project desenvolvido por Martin E. Marty e R. Scott Appleby nos anos 1990. Nesse momento ganhou força a ideia de um "fundamentalismo global", que não estaria mais restrito ao protestantismo e nem aos Estados Unidos, mas que se manifestaria como uma tendência mundial em diversos locais e dentro de diferentes tradições religiosas. Por fim, apresentaremos alguns questionamentos que vêm sendo levantados em pesquisas recentes sobre a real utilidade do uso do conceito de fundamentalismo. 
Em seu formato ampliado - como "fundamentalismo global" - ele não teria se tornado mais um complicador do que uma ferramenta analítica relevante?

\section{Os conceitos e sua história}

Clareza conceitual é um pré-requisito fundamental para o desenvolvimento de reflexões acadêmicas que almejam realizar acréscimos consistentes ao conhecimento acumulado sobre determinado assunto. Seja por uma espécie de reprodução do senso comum, seja pela utilização de uma percepção muito subjetiva - e não explicitada com clareza - sobre determinados conceitos, temos convivido com vários problemas decorrentes da falta de maior atenção dos pesquisadores sobre o conteúdo dos conceitos por eles acionados.

No campo das Ciências da Religião, os usos de certos conceitos - como fundamentalismo, integrismo, tradicionalismo, secularização, entre outros - têm sido marcados pela falta de rigor teórico, tendo seus sentidos ficado implícitos e/ou ao "gosto" do autor que os utiliza. Essa falta de rigor conceitual, entretanto, não é um "espectro" que ronda apenas as Ciências da Religião. Vários autores relevantes das ciências humanas têm explicitado o problemático excesso de sentidos de determinados conceitos que acaba por torná-los analiticamente inócuos. Nos debates sobre o campo político brasileiro, Jorge Ferreira (2001) afirma que "a noção 'populismo' se tornou tão elástica e, de certo modo, a-histórica, que passou a explicar tudo - e, como ocorre nesses casos, a explicar muito pouco" (FERREIRA, 2001, p. 13). Na área da teologia, Francisco Taborda levanta questão semelhante na discussão que faz sobre a concepção de sacramento defendida por Leonardo Boff em Os sacramentos da vida e a vida dos sacramentos (1975). De acordo com Taborda (1989), Boff "amplia tanto a noção de sacramento, identificada com a de simbólico, que tudo se torna sacramento". Taborda (1989) argumenta que "quando um conceito é assim tão ampliado, perde seu significado e já não explica mais nada. Se tudo é sacramento, nada é sacramento: já não se sabe o que são os sete sacramentos nem porque são sete, nem mais nem menos" (TABORDA, 1989, p. 9495). O historiador Robert Darnton (2005) também chega a conclusões próximas às 
de Ferreira e Taborda quando discute a ampliação dos significados de Iluminismo na historiografia recente. Segundo Darnton (2005), o Iluminismo setecentista

\begin{abstract}
tem sido amplificado de tal maneira que não seria reconhecido pelos homens que o criaram. Inicialmente irrigado com uns poucos bons mots em alguns salões parisienses, ele se tornou uma campanha para esmagar l'infâme, uma marcha do progresso, um espírito da época, uma fé secular, uma visão de mundo a ser defendida, combatida ou transcendida, e a fonte de tudo o que era bom, mau e moderno, incluindo o liberalismo, o capitalismo, o imperialismo, o chauvinismo masculino, o federalismo mundial, o humanitarismo da Unesco e a Família Humana. Qualquer um que tenha contas a ajustar ou uma causa a defender começa pelo Iluminismo [...]. O Iluminismo está começando a ser tudo e, portanto, a não ser nada”. (DARNTON, 2005, p. 17-18).
\end{abstract}

Como "deflacionar" conceitos "inflacionados"? O primeiro passo é ter a consciência de que um conceito tem sua própria história e a sua polissemia não deve ser discutida apenas a partir de sua dimensão linguística, mas também a partir de fatores históricos e sociais. Nesse sentido, a chamada História dos Conceitos (Begriffsgeschichte), que tem no historiador alemão Reinhart Koselleck seu principal expoente, fornece importantes perspectivas - ainda pouco exploradas no campo das Ciências da Religião - para pesquisas que trabalhem com as permanências e transformações dos significados de um conceito. Tal abordagem passa pela análise: do surgimento do conceito; de sua etimologia; das diferentes apropriações e significados que um conceito recebeu ao longo da história; e da história dos estudos sobre esse conceito. De acordo com Kirschner (2007), na perspectiva da Begriffsgeschichte, "o estudo dos conceitos e da variação dos seus significados ao longo do tempo é uma condição básica para o conhecimento histórico" (KIRSCHNER, 2007, p. 50). A metodologia da História dos Conceitos seria um instrumento fundamental para "apreender o complexo processo de ressignificações de alguns conceitos ao longo do tempo" (KIRSCHNER?, 2007, p. 50).

A importância dessa discussão se refere, em grande parte, aos questionamentos dos equívocos que podem ocorrer em trabalhos que utilizam conceitos e expressões do presente do pesquisador para a análise do passado. A História dos Conceitos, segundo Koselleck (2006), tem por "exigência 
metodológica mínima a obrigação de compreender os conflitos sociais e políticos do passado por meio das delimitações conceituais e da interpretação dos usos da linguagem feitos pelos contemporâneos de então" (KOSELLECK, 2006, p. 103). No campo da historiografia, uma preocupação recorrente entre os pesquisadores são os riscos de anacronismos conceituais na investigação sobre sociedades do passado. Dado que, segundo Antoine Prost (2012), “o historiador formula, inicialmente, suas questões com os conceitos de sua própria época já que ele os define a partir da sociedade em que vive” (PROST, 2012, p. 117), é perfeitamente compreensível a “tentação" de aplicá-los à análise do passado - um passado para o qual, muitas vezes, tais conceitos (ou o conteúdo atual deles) não faria sentido ou distorceria a sua interpretação.

Todo conceito está associado a uma palavra, mas nem toda palavra é um conceito. Um conceito é caracterizado por ser polissêmico e, para sua devida compreensão, deve ser analisado no contexto social e temporal no qual é acionado. Dessa forma, salienta Kirschner (2007), nesse exercício de contextualização de um conceito, "o recurso a outros textos do período examinado, que possibilitem a construção do contexto histórico no qual se insere aquele determinado conceito, torna-se indispensável” (KIRSCHNER, 2007, p. 51). Koselleck (2007) é enfático ao ressaltar o fato de que a discussão dos conceitos não está confinada à análise de textos e nem a história à dimensão linguística. Esse esforço de contextualização do conceito também deve levar em conta a ideia de que os conceitos formam uma rede, na qual a sua compreensão passa pela discussão de conceitos correlatos (alguns que são imprescindíveis para a teoria que muitas vezes dá origem ao conceito), seus antônimos e outros conceitos de significado próximo (e que podem ser confundidos nos seus usos).

Como pudemos observar, a História dos Conceitos não tem como objetivo central desvelar o sentido original de um determinado conceito, mas sim demonstrar a sua construção histórica. Contextualizar um conceito não é "engessálo" ao seu contexto de surgimento e ao seu significado inicial. Assim, a História dos Conceitos possibilita ao pesquisador uma análise coerente sobre as permanências e 
alterações no sentido de um determinado conceito em diferentes contextos históricos e socioculturais. Além de contextualizar os textos e discursos pesquisados, é necessário entender o sentido do conceito a partir de quem o enuncia. Mesmo pessoas que convivem no mesmo contexto histórico e linguístico podem dar a um conceito significados diferentes. No caso de nossa discussão neste artigo, por muitas vezes o sentido de fundamentalismo, quando enunciado por um teólogo conservador, um teólogo liberal, um jornalista, um cientista político ou um pesquisador do fenômeno religioso possui sentidos bem diferentes.

Devido aos limites deste artigo, não temos como nos aprofundar mais detidamente na perspectiva koselleckiana da História dos Conceitos. Mas, para nossos fins imediatos, cremos que alguns de seus pontos centrais e de suas veredas metodológicas puderam ser apresentadas para o leitor. $\mathrm{Na}$ análise do conceito de fundamentalismo, deve-se estar sempre atento ao significado do conceito em cada contexto e a cada ator social que o enuncia. Buscaremos, na próxima seção, "despir" o conceito de sua controversa carga semântica atual e investigar o sentido original e as primeiras transformações no significado de fundamentalismo no contexto teológico, social e político de seu surgimento - no protestantismo norteamericano do início do século XX.

\section{0 fundamentalismo histórico}

Procuramos, neste texto, realizar uma diferenciação que torna mais inteligível o desenvolvimento histórico do conceito de fundamentalismo em dois momentos determinantes de sua história. O primeiro momento seria o do "fundamentalismo histórico" que remete às raízes e aos desenvolvimentos do conceito em seu contexto geográfico e religioso de origem: o protestantismo norteamericano. Na próxima seção falaremos da ampliação da noção de fundamentalismo para além de seu contexto original com o surgimento da perspectiva de um "fundamentalismo global". 
A história das origens do fundamentalismo é relativamente conhecida, especialmente entre aqueles que pesquisam a história do protestantismo. Como dissemos, sua origem é protestante e norte-americana. Começa como uma polêmica teológica e uma disputa interna dentro dos seminários teológicos e, especialmente a partir do final da Primeira Guerra Mundial, ganha os contornos de um movimento em defesa das "verdades bíblicas” e, também, dos "valores cristãos" na sociedade norte-americana. É um entendimento corrente entre os diversos pesquisadores do período que o primeiro a utilizar o termo foi o batista conservador Curtis Lee Laws em 1920 para definir a sua facção dentro da disputa que se travava entre liberais e conservadores na Convenção Batista do Norte. Mas a história do fundamentalismo se inicia antes do surgimento do conceito.

Os primeiros passos do que viria a ser chamado de fundamentalismo ocorreram nas últimas décadas do século XIX. Nesse período, começaram a ganhar força dentro dos seminários norte-americanos novas perspectivas teológicas vindas da Europa - mais especificamente da Alemanha - que levantaram uma série de discussões dentro dos centros de formação teológica nos Estados Unidos. A tendência dessas novas perspectivas teológicas, que está no cerne da polêmica fundamentalista, era a leitura da Bíblia como um livro "comum", suscetível à interpretação histórico-crítica e que apresentava a incompatibilidade entre as novas descobertas científicas e a noção de que certos relatos bíblicos seriam "verdades históricas". Como exemplo de tais polêmicas, em seu influente $A$ vida de Jesus - lançado originalmente em 1835, mas que em 1869 já possuía uma tradução em inglês circulando pelos Estados Unidos - David Friedrich Strauss desenvolvia o argumento de que o Jesus dos Evangelhos não era histórico e sim mitológico. Para Strauss (1869) "as discrepâncias entre a cultura moderna e os registros antigos, no que diz respeito à sua dimensão histórica, tornam-se tão evidentes que a crença na intervenção direta da divindade nos assuntos humanos perde a sua plausibilidade” (STRAUSS, 1869, p. 12). A ideia do Deus encarnado que nasceu de uma virgem, que andava sobre as águas, multiplicava peixes e pães, transformava água em vinho, fazia paralíticos andarem etc. seria uma invenção posterior da Igreja e fruto de uma 
visão mitológica de mundo. Para o homem moderno, emancipado das superstições e crendices pela "luz da razão", essas crenças não fariam mais sentido.

Logo vozes se levantaram em questionamento a tais argumentos desse chamado modernismo ou liberalismo teológico no protestantismo norteamericano. A primeira reação mais incisiva à propagação dos questionamentos dos liberais em relação à ortodoxia veio do principal bastião do calvinismo mais tradicional: os presbiterianos do Seminário Teológico de Princeton. Archibald A. Hodge e Benjamin B. Warfield (1881, p. 26) afirmavam que a Bíblia não apenas continha, mas era a Palavra de Deus, e todas as suas afirmações eram isentas de erro. Além de inspiradas por Deus e livres de erros, as verdades bíblicas seriam claras e acessíveis a todos os homens em todos os tempos. Todas as gerações encontrariam as mesmas verdades no texto sagrado. Os relatos presentes nas Sagradas Escrituras não seriam, como alguns teólogos do século XIX poderiam afirmar, interpretações do passado a partir de um ponto de vista datado: eles seriam sim a fiel narrativa do que de fato havia acontecido. De acordo com Panasiewicz (2008), essa é uma perspectiva que "não aceita que o texto possa ter mais de um sentido, mesmo que seu entendimento não seja claro ou que contenha aparentes contradições" (PANASIEWICZ, 2008, p. 9).

A "reação conservadora" não se restringiu aos presbiterianos. Logo, movimentos de contestação ao modernismo teológico e em defesa da inerrância do texto bíblico se alastraram pelas mais diferentes denominações protestantes, com mais força entre presbiterianos e batistas. $\mathrm{O}$ conflito entre as duas correntes se acirrou e vários professores e pastores, de parte a parte, sofreram processos internos, foram destituídos de suas cadeiras nos seminários e muitos deles expurgados de suas igrejas. Ao mesmo tempo, começaram a ocorrer encontros, como a Conferência Bíblica de Niágara em 1878, de cristãos conservadores que empreendiam uma grande cruzada nacional contra a proliferação de interpretações consideradas heterodoxas da Bíblia. Um marco nessa luta foi o lançamento de The Fundamentals: a testimony to the truth, uma coletânea de 12 volumes lançados entre os anos de 1910 e 1915, contendo uma série de artigos de teólogos 
conservadores refutando os "erros" do modernismo teológico e reafirmando os pontos inegociáveis da fé cristã "autêntica". ${ }^{2}$

A passagem do que chamamos de polêmica fundamentalista para um efetivo movimento fundamentalista (assim diretamente denominado a partir de 1920) ocorre com uma ampliação progressiva (especialmente após o final da Primeira Guerra Mundial) da batalha contra o mundo moderno. Podemos perceber uma gradual ampliação do escopo das discordâncias: de um conflito inicial dentro dos muros dos seminários limitado a questões do terreno da reflexão teológica, as polêmicas passaram a girar em torno de temas como posicionamento das igrejas frente a problemas sociais, os benefícios (ou não) da nova ordem urbana, a relação entre o cristianismo e as novas descobertas científicas etc. O fundamentalista era, inicialmente, um defensor da fé e da inerrância do texto bíblico, mas também um defensor dos valores cristãos e um combatente ferrenho da "degradação moral" da qual o país era "vítima”. Seu inimigo era o modernismo e tudo o que ele representava.

O país estaria sob a ameaça não só da "falsa teologia", mas também da "falsa ciência” e da propagação de uma concepção equivocada da natureza humana nas escolas e universidades. Os problemas, portanto, não se resumiam à adoção do método histórico-crítico para a interpretação dos textos sagrados. O darwinismo que já vinha sendo condenado pelos conservadores desde o século XIX, tornou-se um símbolo da ameaça a ser combatida. As investidas dos fundamentalistas, visando a proibição do ensino da teoria da evolução das espécies nas escolas públicas, seriam responsáveis pela grande visibilidade que o movimento atingiu na primeira metade da década de 1920.

\footnotetext{
${ }^{2}$ Outra questão que unia a grande maioria das principais lideranças do movimento fundamentalista era a defesa da perspectiva escatológica pré-milenarista/dispensacionalista - que via com pessimismo alguns aspectos do mundo moderno que havia virado as costas para as verdades reveladas e advogava que a redenção da humanidade só ocorreria após a Segunda Vinda de Cristo. 0 dispensacionalismo começou a se disseminar nos Estados Unidos no mesmo período em que o conservadorismo teológico aumentou o tom de suas críticas ao liberalismo. Essa perspectiva escatológica ganhou simpatia de uma grande parte do espectro conservador do protestantismo norte-americano, ao se apresentar como "bíblica", favorecendo uma interpretação literalista da Bíblia em resposta aos questionamentos da interpretação liberal das Escrituras. Seu entendimento era de que todas as expectativas escatológicas descritas no Novo Testamento, pelos apóstolos e por São Paulo, e na história do cristianismo primitivo eram claramente pré-milenaristas. Sobre a história do dispensacionalismo nos Estados Unidos, ver ROCHA (2017).
} 
Em 1923, William Jennings Bryan, político democrata (ex-secretário de Estado e candidato derrotado à presidência por três vezes) e ardoroso fundamentalista, iniciou uma grande cruzada contra o ensino da teoria da evolução nas escolas públicas norte-americanas. No seu ponto de vista, o darwinismo negava as verdades bíblicas e levaria as crianças norte-americanas ao ateísmo e ao abandono dos valores cristãos sobre os quais a nação fora erguida. Bryan lotou auditórios por todo o país, e chamou a atenção da mídia e da opinião pública. A cruzada de Bryan teve grande sucesso no sul dos EUA, onde estados como a Flórida, o Mississipi, o Arkansas e o Tennessee criaram projetos de lei proibindo o ensino das teorias de Darwin em suas escolas.

Na pequena cidade de Dayton, no estado do Tennessee, o jovem professor de Biologia John Scopes foi processado por ensinar a teoria da evolução em suas aulas. O julgamento do caso Scopes mobilizou a imprensa norte-americana da época, ávida por polêmicas que turbinassem suas vendas de jornais. Os grandes órgãos de imprensa do norte dos EUA, partidários de uma cultura moral mais flexível, criaram um grande teatro onde se travariam várias batalhas: ciência versus religião, urbano versus rural, e norte versus sul (MARSDEN, 2001, p. 195). O palco do "espetáculo" - a rural e sulista Dayton no estado do Tennessee - serviu para enfatizar ainda mais tais antagonismos. Para a imprensa, enquanto Bryan representava o mundo rural e "obscurantista", o advogado de defesa $\mathrm{C}, 3$ larence Darrow representava a racionalidade e a sofisticada e moderna cultura urbana. De acordo com Ruthven (2007), o Scopes Trial "foi um dos primeiros exemplos do que viria a ser conhecido como evento de mídia, em que a própria cobertura feita pela imprensa foi mais importante do que o que realmente aconteceu no tribunal" (RUTHVEN, 2007, p. 12). Jornalistas dos principais meios de informação estavam presentes, entre eles o repórter mais famoso da época - e ferrenho crítico do fundamentalismo -, H. L. Mencken do Baltimore Sun. De acordo com Mencken (2002), o fundamentalismo seria uma expressão do ódio dos "homens inferiores" em relação ao conhecimento. A complexidade dos avanços científicos seria um fardo insuportável para os fundamentalistas. "Sua busca é sempre por atalhos. Todas as superstições são atalhos. Seu objetivo é tornar o ininteligível simples e até 
óbvio. [...] A cosmogonia do Gênesis é tão simples que até um caipira pode entendê-la” (MENCKEN, 2002, p. 167).

Susan Harding (1991) afirma que mais de 200 repórteres das maiores cidades dos Estados Unidos realizaram a cobertura do Caso Scopes. Entretanto, apesar da existência de vários periódicos fundamentalistas espalhados pelo país, especialmente nas grandes cidades, nenhum deles enviou "observadores" para Dayton. Muitos não citaram o julgamento ou o fizeram de maneira superficial, como mais um ataque dos liberais e darwinistas à fé bíblica. Dessa forma, o julgamento foi apresentado para a maioria dos norte-americanos a partir da perspectiva dos "modernos". "O ponto de vista dos fundamentalistas, explicitado em suas próprias vozes, foi apagado e depois reinscrito dentro - encapsulado por da metanarrativa moderna nas notícias lidas e ouvidas em todo o país e no exterior” (HARDING, 1991, p. 382).

A divulgação que a imprensa do norte fez do julgamento desacreditou o fundamentalismo junto ao grande público, e o adjetivo fundamentalista, antes ostentado com orgulho, passou a ser sinônimo de ignorância e desinformação. Os fundamentalistas seriam, a priori, inimigos da ciência, das liberdades civis e do progresso. O estereótipo do fundamentalista nada mais tinha a ver com, por exemplo, professores do seminário teológico de Princeton ou pessoas de classe média das cidades do norte.

Encerrando (um pouco bruscamente) esta seção, quando nos referimos a "fundamentalismo histórico", falamos de um movimento religioso, protestante e norte-americano, que surgiu em oposição ao liberalismo/modernismo teológico e defendia uma concepção de inerrância do texto bíblico. Ele se caracteriza, essencialmente, pelo conservadorismo teológico, pelo conservadorismo moral, pelo conservadorismo político, pelo patriotismo e por uma perspectiva escatológica dispensacionalista. Buscava se contrapor ao processo de secularização reafirmando a importância da "verdadeira" religião, tal como expressa nas Sagradas Escrituras, 
como eixo unificador e fonte de sentido das esferas do saber e da atuação dos homens no mundo.

\section{0 fundamentalismo global}

Apesar das transformações que o conceito de fundamentalismo experimentou ao longo do século XX nos Estados Unidos, a sua aplicação a essa parcela mais conservadora do protestantismo norte-americano das décadas de 1920 e 1930 não tem despertado maiores controvérsias entre os pesquisadores. Sua classificação como fundamentalismo e mesmo a autoidentificação como fundamentalistas daqueles envolvidos nas lutas contra o ensino do darwinismo e a "flexibilização" liberal da interpretação dos textos bíblicos dão aos pesquisadores que trabalham com essa temática durante esse período certa tranquilidade para usar o conceito sem maiores constrangimentos. Mas, mesmo no caso norteamericano, esses consensos começaram a se dissolver muito rapidamente após a Segunda Guerra Mundial, no contexto da Guerra Fria.

Se na década de 1930 o número de fundamentalistas, mesmo sob fortes críticas dos setores mais "ilustrados" da população, crescia enquanto a membresia das igrejas liberais diminuía, a partir de meados da década de 1940, o protestantismo norte-americano voltou a crescer como um todo. Segundo Cecília Azevedo (2001, p. 114), "a partir da década de 1940 [...], aumentou 40\% o número de membros das igrejas, e a venda de Bíblias dobrou entre 1947 e 1952, período inicial da Guerra Fria”. A principal força impulsionadora desse novo "avivamento" no protestantismo norte-americano foi o chamado neoevangelicalismo representado nas igrejas organizadas em torno da National Association of Evangelicals (NAE) e que tinha na figura do pastor batista Billy Graham a sua grande "estrela". Os neo-evangelicals enfatizavam a experiência de conversão individual (re-nascimento), tinham grande apego à Bíblia (com interpretações basicamente literalistas) e enfatizavam a importância da pureza moral em suas pregações. Tanto que alguns autores não vêm dificuldade de identificá-los como fundamentalistas. 
Entretanto, esses neo-evangelicals não se identificavam com o discurso sectarista e as reservas em relação às ações sociais do fundamentalismo histórico. Esse tipo de fundamentalismo mais radicalizado, especialmente nas décadas iniciais da Guerra Fria, era mais identificado com figuras como o polêmico Reverendo Carl McIntire. De acordo com Axel Schäfer (2012, p. 10), o neoevangelicalismo do pós-guerra procurou estabelecer-se como uma "terceira força", distinguindo-se tanto do fundamentalismo quando do liberalismo teológico. A "identidade" do neo-evangelicalismo possuía uma série de tensões: entre a devoção religiosa e o crescente ajustamento ao "mundo", entre a ortodoxia teológica e o ecumenismo (um ecumenismo entre as denominações evangélicas) e entre o moralismo tradicional e os valores da modernidade. Além disso, reafirmavam um discurso de separação entre igreja e Estado, mas mantinham proximidade com as estruturas de financiamento governamental para suas instituições educacionais, de saúde e de assistência social. A diferenciação interna do campo protestante norteamericano demandaria uma longa digressão, o que nos afastaria do objetivo proposto para o presente texto. Diferenciar e contextualizar historicamente conceitos como fundamentalismo, evangelicalismo (e a divisão entre white evangelicals e black evangelicals) e classificações como evangelicals, neoevangelicals, Bible-believing Christians, born again Christians entre outros no caso norte-americano é um trabalho hercúleo e cercado por uma série de debates e desacordos entre os pesquisadores.

$\mathrm{Na}$ trajetória do século XX, como retrata David Harrington Watt em Antifundamentalism in modern America (2017), a imagem dos fundamentalistas como inimigos da modernidade e das liberdades foi sendo consolidada no senso comum mas também na academia através de críticas de vários intelectuais que, de certa forma, repercutiram as ácidas críticas de Mencken ao fundamentalismo. Watt (2017) enumera uma série de críticas ao fundamentalismo vindas de figuras importantes como H. Richard Niebuhr, Talcott Parsons - que "sugeria que o fundamentalismo seria simplesmente uma versão do nazismo no Novo Mundo e que o nazismo seria simplesmente uma variante do fundamentalismo na Europa" (WATT, 2017, p. 95) - e Richard Hofstadter. 
O fundamentalismo retornou com força à pauta da imprensa e aos debates acadêmicos nos Estados Unidos a partir de meados da década de 1970. Jerry Falwell, conhecido pastor conservador batista, que se autoidentificava como cristão fundamentalista e possuía um programa de televisão de enorme audiência, tomou a frente do movimento que recebeu o nome de Maioria Moral. Esse movimento se tornou uma grande força política nos EUA e tinha como principais bandeiras: a defesa dos "valores da família" (o que incluía a oposição ao aborto em qualquer caso, o combate à expansão dos direitos dos homossexuais e, também, a restrição à pornografia); a volta da prática das orações e o ensino do criacionismo nas escolas públicas; o combate à disseminação do comunismo juntamente com uma defesa ferrenha do capitalismo e do "modo de vida" americano; a defesa de uma posição pró-Israel por parte do governo norte-americano (uma influência direta das ideias dispensacionalistas); entre outras.

Paralelamente à ascensão dessa nova Direita Cristã nos Estados Unidos, no Irã em 1979 ocorria "em nome de Alá e de Maomé, seu profeta, uma rebelião religiosa desde abajo [que] acabava de botar abaixo, pela força, um regime político também de força, mas laico" (PIERUCCI, 1992, p. 144). Para alguns, as semelhanças entre as ações capitaneadas por Jerry Falwell e pelo Aiatolá Khomeini seriam muito evidentes para serem ignoradas. Essa ressurgência de uma religiosidade politicamente engajada, hostil ao processo de secularização e apegada a valores considerados obsoletos pelo mundo moderno seria a manifestação de um movimento de proporções mundiais.

O debate que nos interessa diretamente aqui é a "ampliação" do conceito de fundamentalismo para além do contexto protestante e norte-americano a partir do final da década de 1970 e o surgimento da noção de um "fundamentalismo global". Em 2014, foi lançado o livro Fundamentalism: perspectives on a contested history, organizado pelo já citado David Harrington Watt e Simon A. Wood, professor do departamento de Religious Studies da Universidade de Nebraska. Na introdução da obra, Watt e Wood afirmam que os diversos autores que escreveram os capítulos do livro apresentam diferentes perspectivas em relação ao uso do conceito de 
fundamentalismo. E tal divergência vem marcando o campo de estudos sobre o tema entre os pesquisadores norte-americanos. Sobre a utilização do conceito de fundamentalismo, existem: 1) os que compreendem que seu uso não seria apenas útil, mas também importante; 2) os que apresentam certa preocupação em relação ao seu uso, mas não o rejeitam; 3) aqueles que entendem que o conceito tem sido mal aplicado em alguns casos importantes; 4) e, por fim, pesquisadores que simplesmente entendem que o uso do conceito não seria útil - traria mais confusão do que ajuda. Buscaremos apresentar alguns dos argumentos defendidos pelas duas tendências mais "extremas” - o primeiro e o último dos grupos mencionados.

O centro de tais discordâncias está, principalmente, na utilização do conceito de fundamentalismo para além do protestantismo norte-americano, berço do "fundamentalismo histórico". A controversa noção da existência de um "fundamentalismo global" ganhou força a partir do início dos anos 1980, sob o impacto do fortalecimento da Direita Cristã nos Estados Unidos e, especialmente, com a revolução iraniana de 1979. Representariam movimentos religiosos de caráter conservador nos quais o vínculo entre religião e política e a crítica à crescente secularização da sociedade seriam as características marcantes.

Dois autores muito importantes na defesa da existência de um “fundamentalismo global” foram Martin E. Marty e R. Scott Appleby, responsáveis pela organização do The Fundamentalism Project, que reuniu vários pesquisadores (cientistas políticos, historiadores, cientistas da religião, sociólogos, psicólogos, antropólogos, entre outros) entre 1987 e 1995 na discussão do crescimento de movimentos religiosos conservadores e politicamente engajados em vários países e em diversas tradições religiosas. Os resultados da pesquisa foram publicados em volumes lançados pela editora da Universidade de Chicago. Segundo Gabriele Marranci (2009), apesar do amplo espectro disciplinar dos autores e das diferentes abordagens do tema, as "conclusões do projeto sugerem que todos os 'fundamentalismos' são consequências de grupos e líderes religiosos conservadores que rejeitam o modernismo e o secularismo", buscando assim "preservar as formas 
tradicionais de vida e as crenças religiosas através do escrituralismo" (MARRANCI, 2009, p. 2).

A concepção de fundamentalismo defendida por Appleby (1998) transborda as fronteiras do fundamentalismo protestante norte-americano e aponta para uma indissociabilidade entre fundamentalismo e ação política:

\begin{abstract}
Fundamentalismo é uma forma moderna de religião politizada pela qual os autointitulados 'verdadeiros fiéis' resistem à marginalização da religião em suas respectivas sociedades. Os fundamentalistas identificam e se opõem aos agentes de tal marginalização (os secularistas) e procuram reestruturar as relações políticas, sociais, culturais e econômicas, além das próprias instituições, de acordo com preceitos e normas religiosas tradicionais (APPLEBY, 1998, p. 280).
\end{abstract}

Essa busca do poder político com o objetivo de transformar (ou restaurar) a sociedade pode ocorrer dentro das "regras do jogo" de uma democracia constitucional - através das eleições e de instrumentos legais de ação política - ou por meio do uso da violência, através de atos de terrorismo, guerras santas e/ou revoluções religiosamente motivadas. A visão dos fundamentalistas - que orienta a sua ação também no campo da política - se apoiaria na crença do seu "monopólio" da verdade absoluta e inerrante e em uma perspectiva dualista (os filhos da luz contra os filhos das trevas). Além disso, Appleby (1998) afirma que os fundamentalistas "acreditam estar vivendo em um período especial da história, talvez os últimos dias, nos qual Deus está atuando de uma nova forma entre os verdadeiros fiéis" (APPLEBY, 1998, p. 281). O conceito de fundamentalismo seria uma chave analítica importante para entender o papel das religiões no mundo contemporâneo e para apontar certas semelhanças em movimentos religiosos de reação à modernidade e à "privatização" da religião que ganhavam força ao redor do mundo no final do século XX - numa espécie de "revanche de Deus", como a denominou Gilles Kepel (1991). 
Os autores que defendem a perspectiva de um fundamentalismo global advogam a presença de elementos em comum, tanto nas crenças básicas quanto no modus operandi desses movimentos. Seria, de fato, comparar o que é comparável. $\mathrm{Na}$ introdução de um dos volumes do Fundamentalism Project, Marty e Appleby (1993, p. 2) defendem que fundamentalismo é “um dispositivo analítico útil” em estudos comparativos que englobem movimentos dentro de tradições religiosas diversas. Existiriam "semelhanças familiares" entre diversos "movimentos religiosamente inspirados de reação a processos globais de modernização e secularização no século XX”. "Fundamentalistas judeus, cristãos e muçulmanos podem não compartilhar as mesmas crenças específicas, mas eles compartilham um modo de pensar a respeito de suas crenças” (APPLEBY, 1998, p. 281). Dessa forma, apesar de outras tradições religiosas não possuírem certas características que poderiam ser identificadas com mais clareza dentro dos três grandes monoteísmos, Appleby (1998) entende que características do fundamentalismo podem ser encontradas em outros movimentos religiosos como "nacionalistas hindus na Índia, radicais sikh em Punjab e militantes budistas no Sri Lanka” (APPLEBY, 1998, p. 281). A dimensão política (muitas vezes nacionalista) e intolerante desses movimentos os aproximaria de uma "tendência fundamentalista" que se espalhava pelo mundo afora.

Se a caracterização do "fundamentalismo histórico" nos permite ter certa clareza sobre o significado do conceito, a ampliação de seu uso para diferentes contextos históricos, geográficos e religiosos é feita às custas de sua precisão. $\mathrm{Na}$ busca das "semelhanças familiares", o fundamentalismo se afasta da especificidade do "fundamentalismo histórico" para se transformar em uma espécie de "espírito do tempo" ou, nas palavras de Marty e Appleby (1993) "uma tendência”, "um habit of mind". Leonardo Boff, cuja perspectiva é muito influente entre pesquisadores brasileiros, fala de uma "atitude fundamentalista" (MARTY; APPLEBY, 1993, p. 3). O fundamentalismo "não é uma doutrina. Mas uma forma de interpretar e viver a doutrina” (BOFF, 2002, p. 25). Em entrevista dada à Revista IHU em o8 de outubro de 2014, Leonardo Boff afirma que: 
A atitude fundamentalista surge quando a verdade de sua igreja ou de seu grupo é entendida como a única legítima com a exclusão de todas outras, tidas como errôneas e por isso destituídas do direito de existir. Quem imagina ser seu ponto de vista o único válido está condenado a ser intolerante. Esta atitude fechada leva ao desprezo, à discriminação e à violência religiosa ou política. ${ }^{3}$ (BOFF, 2014).

Se para Appleby (1998) "fundamentalistas podem ser encontrados em qualquer religião histórica que tenha escrituras sagradas e ensinamentos básicos" (APPLEBY, 1998, p. 280), Boff (2002) vai um pouco mais longe e afirma que "o fundamentalismo, como atitude e tendência, se encontra em setores de todas as religiões e caminhos espirituais" (BOFF, 2002, p. 26). Partindo-se dessa premissa da "atitude fundamentalista", alguns questionamentos aparecem: Se há fundamentalismo em todas as religiões, pode haver fundamentalismo sem livros sagrados?; Se entender a verdade do seu próprio grupo como a única legítima é ser fundamentalista, podemos falar em fundamentalismo antes do advento da modernidade? (teria Galileu Galilei sido vítima da perseguição de fundamentalistas?). A busca por "semelhanças de família" não teria feito com que os pesquisadores ignorassem o fato de que há muito mais diferenças do que semelhanças entre os grupos religiosos considerados conservadores e politicamente mobilizados? Não poderíamos nos perguntar aqui, junto com Marranci (2009), se tais “'semelhanças de família' existem mais nas mentes daqueles que escrevem sobre o fundamentalismo do que nos fenômenos sobre os quais eles escrevem"? (MARRANCI, 2009, p. 6).

\section{Criando o fundamentalismo}

A noção de um "fundamentalismo global" é, de fato, um capítulo importante na história do conceito de fundamentalismo e está na raiz de sua atual polissemia. $\mathrm{O}$ uso do conceito tem se tornado cada vez mais comum nos textos acadêmicos, na mídia e mesmo no senso comum. E o uso, na quase totalidade das vezes, é acusatório e direcionado a uma pessoa ou grupo diferente daquele que o enuncia. Além disso, não está mais limitado à questão religiosa. É necessário acrescentar

\footnotetext{
3 A doença do fundamentalismo. Disponível em: http://www.ihu.unisinos.br/78-noticias/536010-a-doenca-do-fundamentalismoleonardo-boff. Acesso em: 25 jul. 2020.
} 
"religioso" a fundamentalismo para diferenciá-lo dos inúmeros fundamentalismos que se criaram. Em Juan José Tamayo, podemos ter uma noção da "polivalência" contemporânea do conceito. Segundo o autor, fundamentalismo

consiste en la absolutización de una verdad, religión, cultura etc., que se pretende imponer, incluso recorriendo a la fuerza, como la única y universalmente válida [...]. Así, se habla de fundamentalismo religioso, cuando uma religión se considera la única verdadera; de fundamentalismo político, cuando se absolutiza un único modelo político com exclusión del resto; [...] de fundamentalismo económico, cuando se defiende la existencia de un único modelo de economía, en concreto el de mercado, com su correspondiente teología neoliberal. (TAMAYO, 2009, p. 17).

Como dissemos na seção anterior, se existem autores que defendem o uso do conceito de fundamentalismo em análises comparativas e que ultrapassam o contexto protestante e norte-americano no qual o conceito surgiu, por outro lado, vários autores vêm manifestando preocupações com uso indiscriminado do conceito. De acordo com Watt e Wood (2014, p. 5), entre os críticos do uso ampliado de fundamentalismo alguns entenderam que o conceito não é útil e que ele mais obscurece do que esclarece; outros afirmam que ele permanece muito ligado a concepções cristãs para ser aplicado de maneira significativa a outras tradições religiosas; e também há aqueles que entendem que o conceito tornou-se muito vago para ser útil. "De maneira geral, o fundamentalismo é definido em termos de resistência às 'ameaças' modernas ou oposição ao moderno secularismo. Para além disso, é difícil determinar com precisão o que as palavras fundamentalismo e fundamentalista significam” (WOOD, 2014, p. 125). A posição de Peter Berger (2000) em relação ao uso de fundamentalismo para classificar alguns setores do islamismo exemplifica o tom principal dos críticos:

Tanto na mídia como em publicações acadêmicas, esses movimentos são muitas vezes englobados na categoria "fundamentalismo". Este não é um termo feliz, não só porque carrega um tom pejorativo, mas também porque deriva da história do protestantismo norte-americano, onde tem uma referência específica que acaba distorcida quando estendida para outras tradições religiosas [...] Se as características comuns acima citadas são importantes, uma análise do impacto social e político dos vários surtos religiosos também precisa considerar seriamente as diferenças entre eles (BERGER, 2000, p. 13-14). 
Percebemos entre os adeptos e os críticos do uso do conceito uma diferença básica de enfoque: enquanto os favoráveis à noção de um "fundamentalismo global” dão destaque às semelhanças, seus críticos enfatizam as diferenças. As diferenças seriam muito mais claras do que as "semelhanças familiares" e a busca pelo que haveria de comum em movimentos tão diferentes seria responsável pela perda de capacidade explicativa do conceito. Ele, na verdade, seria uma "pedra de tropeço", pois tenderia a obscurecer as diferenças e a homogeneizar fenômenos muito diferentes em uma classificação comum.

A utilidade do uso ampliado do conceito de fundamentalismo também é questionada devido ao fato de que o seu uso substitui outras palavras e conceitos que seriam muito mais adequados ao fenômeno analisado do que a atualmente difusa noção de fundamentalismo. Chamar as coisas pelo nome seria optar pela especificidade ao invés da generalização. Muitas vezes, dependendo do contexto em que é acionado, fundamentalismo pode ser substituído por intolerância, exclusivismo, sectarismo ou intransigência sem nenhuma perda no conteúdo da frase. Pelo contrário: haveria um ganho significativo em termos de clareza de sentido. Se intransigente, de acordo com o Dicionário Michaelis, 4 significa "aquele que não transige, que não faz concessão; austero, intolerante, rigoroso, severo; [...] que revela austeridade de caráter e rigidez na observância de princípios”, não seria mais recomendável falar, em vários casos, de intransigência religiosa ao invés de fundamentalismo? Se fanatismo significa "excessivo zelo religioso que, às vezes, beira a obsessão e pode resultar em atitudes extremistas de intolerância; adesão cega a uma doutrina ou sistema; faccionismo, partidarismo", a noção de fanatismo religioso, em alguns casos, não seria mais apropriada do que a atual polissêmica noção de fundamentalismo?

Sem estabelecer uma lista completa, ressaltamos a sugestão de Khalid Yahya Blankinship de que frequentemente o que é discutido sob a rubrica de fundamentalismo é efetivamente separatismo ou exclusivismo. Por que não se referir a esses casos como tal? Qual seria a vantagem de rotulá-los como fundamentalismo? Nós nos esforçamos para conseguir encontrar alguma. [...] Se o que realmente procuramos evocar é uma categoria de pessoas religiosas que são propensas à violência ou militância, então faria

4 Versão digital disponível em: http://michaelis.uol.com.br/. Acesso: em 24 jul. 2020. 
sentido para nós focarmos na comparação de "formas militantes de religião" ou "formas violentas de religião". Da mesma forma, se nosso objeto são religiões politizadas - uma reação a questões políticas baseadas no recurso à tradição religiosa - por que não se referir a elas como tal? [...] Com certeza, termos como Islã político [no original Political Islam] trazem seus próprios conjuntos de complicações e controvérsias, mas são, na nossa perspectiva, menos problemáticos do que aqueles associados com fundamentalismo (WATT; WOOD, 2014, p. 254).

Além dessa corrente de autores que se contrapõem diretamente à perspectiva de um "fundamentalismo global”, há outros que questionam outras implicações do uso do conceito de fundamentalismo. Uma discussão importante se dá em torno da carga pejorativa do conceito e da análise daqueles que o enunciam. É claramente perceptível no uso prático do conceito que “o fundamentalismo continua a ser o lugar simbólico do outro: nós [grifo do autor] não somos fundamentalistas, eles é que são" (CAMPOS, 2018, p. 356).

Peter Burke (2004) nos oferece uma importante reflexão sobre a nossa relação com o Outro. Segundo o historiador inglês, grupos confrontados com culturas diferentes reagiriam: 1) negando ou ignorando a distância cultural, assimilando "os outros a nós mesmos ou a nossos vizinhos pelo uso de analogia, seja esse artifício empregado consciente ou inconscientemente [...] É através da analogia que o exótico se torna inteligível, domesticado;5 ou 2) construindo, consciente ou inconscientemente, a imagem de uma outra cultura como oposta à sua. "Nessa ótica, seres humanos como nós são vistos como 'outros". Na Idade Média, cristãos, inspirados pela Canção de Rolando, entendiam o Islã como uma "inversão diabólica do cristianismo" na qual os muçulmanos adoravam "uma trindade infernal composta de Apolo, Muhammad e um certo 'Termagant" (BURKE, 2004, p. 153-154). Tais atitudes, ao longo da história, estariam na origem da formação de estereótipos, de generalizações baseadas em percepções preconcebidas que não se aprofundavam (e muitas vezes não se interessavam por) no conhecimento de determinada cultura ou grupo. O estereótipo, mesmo que apresente alguns elementos efetivamente comprováveis, ignora certas

\footnotetext{
5 Burke exemplifica tal posição recorrendo ao exemplo do navegador Vasco da Gama que, ao entrar em um templo hindu pela primeira vez, interpretou uma escultura de Brahma, Vishnu e Shiva como uma representação da Santíssima Trindade. Da mesma forma, os cruzados viam Saladino como um cavaleiro, de acordo com os padrões cristãos e europeus.
} 
particularidades e generaliza o que é diverso. Além disso, o estereótipo, normalmente é negativo. Muitas vezes implica a desumanização do "Outro". De acordo com Burke (2004):

\begin{abstract}
Infelizmente, a maioria dos estereótipos de outros - judeus vistos por não-judeus, muçulmanos por cristãos, negros por brancos, camponeses por pessoas da cidade, soldados por civis, mulheres por homens, etc. - era ou é hostil, desdenhosa, ou no mínimo condescendente. Um psicólogo provavelmente buscaria o medo subjacente ao ódio e também a projeção inconsciente de aspectos indesejáveis do eu no outro. Talvez seja por essa razão que os estereótipos tomam a forma de inversão da auto imagem do espectador. Os estereótipos mais grosseiros estão baseados na simples pressuposição de que "nós" somos humanos ou civilizados, ao passo que "eles" são pouco diferentes de animais (...). Dessa forma, os outros são transformados no "Outro". Eles são transformados em exóticos e distanciados do eu. E podem mesmo ser transformados em monstros. (BURKE, 2004, p. 157).
\end{abstract}

Tendo em vista as críticas dos contrários ao uso da noção ampliada de fundamentalismo, o uso do conceito fundamentalismo e do adjetivo fundamentalista não teria se tornado uma espécie de estereotipagem que deixa marcas indeléveis tanto no senso comum quanto nas reflexões acadêmicas? Dando um passo adiante: o uso corrente da noção de fundamentalismo ao invés de descrever algo objetivo não estaria, de fato, "criando" o fundamentalismo? Se uma das características atribuídas ao fundamentalismo seria uma visão dualista de mundo (os eleitos de Deus contra os filhos das trevas), o discurso moderno sobre o fundamentalismo não seria também uma forma de divisão do mundo entre "nós" e "eles"? Como diz Susan Harding (1991) sobre o caso norte-americano, "os fundamentalistas criaram a si mesmos através de suas próprias práticas culturais, mas não exatamente nos seus próprios termos" (HARDING, 1991, p. 373-374). Eles também foram moldados através de "práticas discursivas modernas", nos esteriótipos populares, nas representações midiáticas e no conhecimento acadêmico. Retornando às repercussões do Scopes Trial, Harding (1991) vê, nos discursos de Mencken e daqueles que foram por ele "inspirados", os fundamentalistas como uma categoria inferior de pessoas cuja existência em pleno século XX necessitava de explicação. O processo de "esclarecimento" ocidental teria falhado em algum ponto para que aquele tipo de manifestação ainda se fizesse 
presente. Se a existência dos fundamentalistas carecia de explicação, por outro lado a cobertura midiática e as repercussões do julgamento no Tennessee constituíramse como "uma apoteose do olhar moderno, de seu ponto de vista autoral, de sua voz de conhecimento, do seu privilégio teleológico e de seu direito de existir sem necessidade de explicação" (HARDING, 1991, p. 390-391).

Gabriele Marranci (2009) afirma que a "criação" do fundamentalismo islâmico está intimamente relacionada ao discurso ocidental, europeu e herdeiro de ênfases iluministas. Numa linha semelhante à conhecida discussão sobre o orientalismo de Edward Said (1990) - o Oriente como uma invenção do Ocidente Marranci discute as implicações de um olhar eurocêntrico e que vê no Iluminismo europeu o ponto de partida e o "padrão de julgamento" para a adequação ou não de certos fenômenos à civilização moderna. O que tem sido entendido como "semelhanças familiares" entre os diversos "fundamentalismos" ao redor do mundo seriam mais consequência de um olhar calcado numa perspectiva histórica evolucionista e europeia e uma metodologia comparativa reducionista, na qual as diversas expressões religiosas seriam medidas pela "régua" de uma religião adequada aos princípios iluministas e secularizantes: respeitando-se a autonomia das demais esferas de atuação humana e condicionada à esfera das crenças privadas. ${ }^{6}$ Nessa perspectiva, o fundamentalismo seria um "fenômeno socioreligioso, caracterizado por se desviar da maneira aceitável de viver no mundo contemporâneo (ocidental/ocidentalizado)" (MARRANCI, 2009, p. 45). Essa visão de fundamentalismo seria então, como advoga Watt (2017, p. 45), herdeira de uma tradição de pensamento antifundamentalista, que defende uma divisão binária do mundo entre os adeptos do progresso e dos valores do mundo moderno (entre eles a democracia e a tolerância) e os reacionários, intolerantes e "inimigos do progresso".

Por fim, não teria esse "olhar moderno" sobre o fundamentalismo se arraigado na academia, mesmo entre os pesquisadores que se dedicam aos estudos

\footnotetext{
${ }^{6}$ Um exemplo dessa contestação a uma noção de religião alicerçada em uma perspectiva europeizada e "iluminista" é a crítica que Talal Asad (1993) faz à perspectiva de Clifford Geertz de religião como um "sistema cultural".
} 
das religiões? Não estaríamos sendo conduzidos por uma diferenciação normativa entre "boa religião" e "má religião" (da qual fundamentalismo seria uma espécie de sinônimo)? Fundamentalismo não teria se tornado uma categoria mais ideológica do que crítica (transformando-se assim numa categoria vazia, quando não problemática)? (WATT; WOOD, 2014, p. 6). O conceito não teria se tornado uma classificação para posicionamentos com os quais eu não concordo (mesmo para além da religião, como a citação de Tamayo no início desta seção mostra)? Teria o pesquisador o papel de juiz sobre a "qualidade" das expressões religiosas que analisa? Seria a crença de que os valores religiosos devem permear todas as esferas de atuação humana uma crença claramente irracional e/ou exótica?

\section{Conclusão}

Como procuramos apresentar ao longo deste texto, as "batalhas" em torno do conceito de fundamentalismo ainda estão longe do fim. A história do conceito continua a ser escrita. De nossa parte, tendemos a adotar uma postura crítica em relação à utilização do conceito de fundamentalismo fora do contexto protestante. Cremos que os exercícios comparativos baseados na noção de "fundamentalismo global” e a aplicação do conceito para além do seu contexto original e mesmo para além de grupos religiosos tem colaborado para uma perda de objetividade e de capacidade explicativa do conceito. Parafraseando Ferreira, Taborda e Darnton, o fundamentalismo está começando a ser tudo, portanto...

Mas também não restringimos o uso da noção de fundamentalismo apenas aos Estados Unidos das décadas de 1920 e 1930. De fato, os elementos centrais daquele fundamentalismo inicial ainda reverberam ao longo da história dos Estados Unidos e, também, em grupos protestantes fora dos Estados Unidos, mas influenciados por algumas tendências do protestantismo norte-americano. Entretanto, tais aplicações devem ser levadas em conta as especificidades históricas e sociais locais e a aplicabilidade ou não do conceito a cada caso. 
Apesar disso, este texto não tem pretensões dogmáticas ou normativas. Os pesquisadores, ao trabalhar com certos conceitos, se veem diante do risco de dois possíveis problemas: ou de se prender a um uso extremamente restrito ou de um uso exageradamente aberto do conceito. Não entendemos como um "pecado mortal" o uso do conceito em exercícios comparativos inspirados pela noção de "fundamentalismo global". Um conceito não está condenado a um confinamento em sua formulação inicial. Fundamentalismo não está preso à concepção que Curtis Lee Laws tinha dele quando pela primeira vez fez uso do conceito. Koselleck (2006) afirma que, "uma vez cunhado, um conceito passa a conter em si, do ponto de vista exclusivamente linguístico, a possibilidade de ser empregado de maneira generalizante, de construir tipos ou permitir ângulos de vista para comparação" (KOSELLECK, 2006, p. 115). Entretanto, esse uso não pode ser feito às custas de falta de precisão conceitual e de tentativas de "comparar o incomparável", de "sufocar" as muitas diferenças para realçar as poucas semelhanças. Entretanto, cabe a cada pesquisador o esforço por deixar claro do que está falando. Como diria Pierucci (1998) sobre o caso de secularização, é necessário "um pouco mais de rigor lógico e precisão conceitual com vistas a diminuir a equivocidade do vocábulo" (PIERUCCI, 1998, p. 65).

\section{REFERÊNCIAS}

APPLEBY, R. Scott. Fundamentalism. In: WUTHNOW, Robert (ed.). The encyclopedia of politics and religion. London: New York: Routledge, 1998. p. 280-288.

ASAD, Talal. Genealogies of religion: discipline and reasos of power in Christianity and Islam. Baltimore: The Johns Hopkins University Press, 1993.

AZEVEDO, Cecília. A santificação pelas obras: experiências do protestantismo nos EUA. Tempo, Rio de Janeiro, v. 6, n. 11, p. 111-129, 2001.

BERGER, Peter. A dessecularização do mundo: uma visão global. Religião e Sociedade, Rio de Janeiro, v. 21, n. 1, p. 9-24, 2000.

BOFF, Leonardo. Fundamentalismo: a globalização e o futuro da humanidade. Rio de Janeiro: Sextante, 2002. 
BURKE, Peter. Testemunha ocular: história e imagem. Bauru: EDUSC, 2004.

CAMPOS, Breno Martins. A exclusão do outro na história do mesmo: uma tentativa nova de classificar o velho fundamentalismo religioso. Religare, Paraíba, v. 15, n. 2, p. 354-381, dez. 2018.

DARNTON, Robert. Os dentes falsos de George Washington: um guia não convencional para o século XVIII. São Paulo: Companhia das Letras, 2005.

DIAS, Zwinglio Mota (org.). Os vários rostos do fundamentalismo. São Leopoldo: Oikos, 2009.

DREHER, Martin Norberto. Fundamentalismo. São Leopoldo: Sinodal, 2006.

FERREIRA, Jorge. O populismo e sua história: debate e crítica: Rio de Janeiro, Civilização Brasileira, 2001.

GOMES, Angela de Castro. Populismo e ciências sociais no Brasil: notas sobre a trajetória de um conceito. In: FERREIRA, Jorge (org.). O populismo e sua história: debate e crítica. Rio de Janeiro: Civilização Brasileira, 2001. p. 17-57.

HARDING, Susan F. Representing fundamentalism: the problem of the repugnant cultural other. Social Research, v. 58, n. 2, p. 373-393, 1991.

HARDING, Susan F. The book of Jerry Falwell. New Jersey: Princeton University Press, 2000.

HODGE, Archibald A., WARFIELD, Benjamin B. Inspiration. Philadelphia: Presbyterian Board of Publication, 1881.

KEPEL, Gilles. A revanche de Deus: cristãos, judeus e muçulmanos na reconquista do mundo. São Paulo: Siciliano, 1991.

KIRSCHNER, Tereza Cristina. A reflexão conceitual na prática historiográfica. Textos de História, v. 15, n. 1/2, p. 49-61, 2007.

KOSELLECK, Reinhart. Futuro passado: contribuição à semântica dos tempos históricos. Rio de Janeiro: Contraponto; Ed. PUC-Rio, 2006.

MARDSEN, George M. Fundamentalism and American Culture. $2^{\mathrm{a}}$ ed. New York: Oxford University Press, 2006.

MARRANCI, Gabriele. Understanding muslim identity: rethinking fundamentalism. New York: Palgrave MacMillan, 2009.

MARSDEN, George M. Religion and American culture. 2. ed. Harcourt College Publishers, 2001. 
MARTY, Martin E.; APPLEBY, R. Scott (ed.). Fundamentalism and society: reclaiming the sciences, the Family and education. Chicago: University of Chicago Press, 1993.

MENCKEN, H. L. On religion. Edited by S. T. Joshi. New York, Prometheus Books, 2002.

ORO, Ivo Pedro. O outro é o demônio: uma análise sociológica do fundamentalismo. São Paulo: Paulus, 1996.

PACE, Enzo; STEFANI, Piero. Fundamentalismo religioso contemporâneo. São Paulo: Paulus, 2002.

PANASIEWICZ, Roberlei. Olhar hermético ou hermenêutico: fundamentalismo religioso, origens e desafios. Atualidade Teológica, Rio de Janeiro, v. 29, p. 1-11, 2008.

PIERUCCI, Antônio Flávio. Fundamentalismo e integrismo: os nomes e a coisa. Revista USP, São Paulo, n. 13, p. 144-156, 1992.

PIERUCCI, Antônio Flávio. Secularização em Max Weber: da contemporânea serventia de voltarmos a acessar aquele velho sentido. Revista Brasileira de Ciências Sociais, São Paulo, v. 13, n. 37, p. 43-73, 1998.

PROST, Antoine. Doze lições sobre a história. 2. ed. Belo Horizonte: Autêntica, 2012.

ROCHA, Daniel. Fim dos tempos nos Estados Unidos: escatologia, fundamentalismo religioso e identidade nacional em Hal Lindsey e Tim LaHaye (1970-1980). Belo Horizonte, 2017. 402 f. Tese (Doutorado em História) - Faculdade de Filosofia e Ciências Humanas, Universidade Federal de Minas Gerais.

RUTHVEN, Malise. Fundamentalism: a very short introduction. Oxford: Oxford University Press, 2007.

SAID, Edward. Orientalismo. São Paulo: Companhia das Letras, 1990.

SCHÄFER, Axel R. Piety and public funding: evangelicals and the State in modern America. Philadelphia: University of Pennsylvania Press, 2012.

SCOFIELD, Cyrus I. (ed.). The Scofield Reference Bible. New York: Oxford University Press, 1967. [A primeira versão da Bíblia de Estudo Scofield foi publicada nos Estados Unidos em 1909, sendo reeditada em 1917 e 1967].

STRAUSS, David Friedrich. The life of Jesus. New York: Calvin Blanchard, 1869.

TABORDA, Francisco. Sacramentos, práxis e festa. Perspectiva Teológica, Belo Horizonte, v. 21, n. 23, p. 85-99, 1989.

TAMAYO, Juan José. Fundamentalismos y diálogo entre religiones. $2^{\mathrm{a}}$ ed. Madrid: Editorial Trotta, 2009. 
WATT, David Harrington. Antifundamentalism in modern America. Ithaca; London: Cornell University Press, 2017.

WATT, David Harrington. The meaning and end of fundamentalism. Religious Studies Review, Houston, v. 30, n. 4, p. 271-274, 2004.

WATT, David Harrington; WOOD, Simon A. Fundamentalism: perspectives on a contested history. Columbia: The University of South Carolina Press, 2014.

WOOD, Simon A. The concept of Global Fundamentalism: a short critique. In: WATT, David Harrington; WOOD, Simon A. Fundamentalism: perspectives on a contested history. Columbia: The University of South Carolina Press, 2014. p. 125-143. 